care, the old Public Education document being very out of date. This will involve all specialist sections and will lead to new policy and new public education documentation. The discovery that some of our policy statements are out of date has led to a proposal that all new statements should have a lifespan determined by Council when accepted as Council reports. All old policy statements are being reviewed and each will be dropped as irrelevant, modified to bring them up to date or rewritten until no College policy statement is available without an identified currency.

The College has also been requested to take part in an important element of the work of the
London Implementation Group, which has set up a mental health reference group to guide it when modifying the acute health sector of London's 16 health authorities and 33 boroughs. The Registrar is a member of this group and is seeking, with other members of the group, to ensure that the work is of an appropriate duration and has sufficient legitimacy to have a genuine impact in supporting and developing the mental health services of London including primary, secondary and tertiary services.

Professor CHRIS THOMPSON, Registrar, Royal College of Psychiatrists

\title{
NHS Management Executive guidance for staff on relations with the public and the media
}

Concern has been expressed within the College in respect of paragraph 27 of the above NHS Management Executive guidance, which could be interpreted as meaning that staff who chose to consult their Members of Parliament might face disciplinary action.

The College has therefore sought clarification from the Department of Health, and the following written assurance has been received from the NHS Management Executive.
"Staff are completely free to consult their MP any time on any issue, and by doing so, they would not be liable for any disciplinary action. This is their constitutional right and the guidance does not aim to compromise this position."

VANessa CAmeron, Secretary, Royal College of Psychiatrists

\section{Business Meeting}

There will be a Business Meeting of the College, to be held in the Council Room at the Royal College of Psychiatrists at $4.30 \mathrm{pm}$ on Wednesday 23 March 1994. All Members of the College are welcome to attend this meeting.

\section{Agenda}

1. Confirmation of the minutes of the previous meeting on 2 February 1993. These minutes will be tabled at the meeting and thereafter published in the Psychiatric Bulletin in April. 2. Obituary.

3. Report of the Registrar.

4. Resolutions (if any). 